\title{
Análise comparativa do ambiente de aviários de postura com diferentes sistemas de acondicionamento
}

\author{
$\overline{\text { Guilherme Vitorasso }^{1} \text { \& Danilo F. Pereira }}{ }^{2}$
}

\begin{abstract}
RESUMO
As tipologias dos galpões de galinhas poedeiras e os materiais utilizados principalmente na cobertura são determinantes para uma condição térmica apropriada com vistas à produção. Neste contexto, o objetivo deste trabalho foi identificar diferenças no ambiente interno de dois galpões de poedeiras, utilizando monitoramento e posterior comparação estatística das variáveis do ambiente. A análise dos dados não evidenciou maior conforto térmico no galpão recoberto com telhas de barro, em razão da ausência de lanternim que dificultou a renovação do ar por "efeito chaminé". A concentração de amônia medida no interior de ambas as instalações ficou dentro do limite de conforto. O índice de temperatura e umidade do galpão recoberto com telhas de cerâmica apresentou valores maiores que do galpão recoberto com telha de cimento amianto, mesmo se verificando temperaturas de superfície menores nas telhas de cerâmica, evidenciando os efeitos positivos do lanternim na instalação. Com base nos resultados desta pesquisa, recomendam-se, para a região de Bastos, SP, que os aviários para galinhas de postura sejam construídos com lanternim e prolongamento do beiral e que sejam recobertos com telhas de cerâmica.
\end{abstract}

Palavras-chave: tipos de cobertura, conforto térmico, ambiência animal

\section{Comparative analysis of the environment of poultry sheds with different systems of acclimatization}

\begin{abstract}
Poulty house typology and the materials used (mainly for roofing) are the determining factors for an appropriate thermal condition aiming at production. In this context, the main point of this paper was to identify differences in the internal environment of two poultry houses, using monitoring and afterwards using statistics for comparing the environmental variables. The data analyzed did not show evidence of better thermal comfort for the house which was covered with ceramic roofing tile, because this house did not have ridged vents, making the hot air exit from the house difficult by the "chimney effect". The ammonia concentration measured inside both houses was within the comfort limit. The temperature and humidity index of the house covered with ceramic roofing tiles was higher than the house which was covered with cement asbestos roofing tile, even though lower temperature on the tiles' surfaces was verified, showing the positive effects of the use of ridge vents at the housing. Based on the results obtained it is recommended for the Bastos, SP region, that poulty houses should be built with the ridge vent and long eaves beyond the roof of ceramic tiles.
\end{abstract}

Key words: roof types, thermal comfort, animal environment

1 Graduando em Administração, Campus Experimental de Tupã - UNESP. Av. Domingos da Costa Lopes, 780. CEP 17603-630, Tupã, SP. Fone: (14) 3404-4200. E-mail: peter unesp@yahoo.com.br

2 UNESP, Campus Experimental de Tupã, Av. Domingos da Costa Lopes, 780. CEP 17603-630, Tupã, SP. Fone: (14) 3404-4200, ramal: 4218. E-mail: danilo@tupa.unesp.br 


\section{INTRODUÇÃO}

Na avicultura moderna existem diversos fatores concorrentes para a criação de um ambiente adequado para a produção. Dentre esses fatores se destacam a temperatura do ar, a umidade relativa do ar, a poeira, a ventilação, a concentração de amônia, a densidade de criação e a limpeza e desinfecção dos galpões (Miragliotta, 2000).

O ambiente de produção é um dos principais causadores de perdas na produção animal em escala industrial. Em relação à variável temperatura do ar, esta se apresenta como o principal fator do ambiente causador de perdas. De acordo com Nääs (1992) a produtividade ideal pode ser obtida quando a ave estiver vivendo em ambiente com temperatura adequada, sem qualquer desperdício de energia metabolizável, tanto para compensar o frio como para acionar seu sistema de refrigeração a fim de resistir ao calor ambiental. Havendo estresse térmico, tanto o desempenho dos trabalhadores quanto o das aves, pode ser afetado. $\mathrm{O}$ estresse térmico nas aves pode acarretar diminuição da ingestão de alimento e das atividades físicas, além de perdas na produção, tais como diminuição na quantidade de ovos produzidos, aumento dos ovos com má formação e até o óbito das aves.

As tipologias dos galpões e os materiais utilizados principalmente na cobertura são determinantes para uma condição térmica adequada com vistas à produção de aves. O calor gerado pelas aves e aquele proveniente da radiação solar, são as duas fontes principais de calor no interior dos edifícios. Dentre as radiações que atuam dentro da instalação, a proveniente do telhado atua com maior intensidade constituindo a variável mais importante (Tinôco, 2001). A ave sente este calor e exprime sua resposta com baixa produtividade (Esmay, 1982).

De acordo com Campos (2000) em regiões de clima tropical as aves, mesmo alojadas em ambientes cobertos, ficam expostas a cargas térmicas de radiação maior que sua produção de calor metabólico. Esta radiação indireta ou difusa intensifica o estresse térmico das aves. Para estimar esse estresse, diversos índices de conforto, criados inicialmente para humanos, foram adaptados para animais. Dentre os índices mais utilizados para a avaliação do conforto térmico estão o índice de temperatura de globo e umidade, proposto por Bufington et al. (1981), e a carga térmica de radiação, proposta por Esmay (1982). Ambos os índices utilizam a temperatura de globo negro para refletir os efeitos da radiação sobre as aves.

Santos et al. (2005) avaliaram o índice de temperatura de globo negro e umidade e a carga térmica de radiação de aviários, em escala reduzida, construídos com materiais de cobertura e projetos de telhados diferentes e observaram que os telhados com lanternim propiciaram melhores condições térmicas. Mazon et al. (2006) também afirmam que a presença do lanternim é fundamental para alcançar o grau de conforto térmico adequado no interior de galpões; esta abertura no telhado proporciona uma renovação melhor do ar e melhora a iluminação natural do interior do galpão.

Jácome et al. (2007) estudando o comportamento térmico de diferentes materiais de cobertura para instalações de poedeiras, constataram que telhados de telha cerâmica apresentaram resultados melhores de carga térmica de radiação nos horários mais quentes do dia, quando comparados com telhados recobertos com telhas de cimento amianto, porém não observaram diferenças significativas nas variáveis temperatura do ar, umidade relativa do ar e índice de temperatura de globo negro e umidade. Furtado et al. (2003) estudaram os efeitos de diferentes tipos de telha em aviários para frangos de corte sem lanternim, mas não verificaram diferenças significativas nas variáveis temperatura do ar, umidade relativa do ar, índice de temperatura de globo e umidade e carga térmica de radiação entre galpões recobertos com telhas de cerâmica e com telha de cimento amianto em todos os horários de medições, que foram entre às 8 e $16 \mathrm{~h}$.

Além do ambiente térmico no interior da instalação é importante que se avalie a qualidade do ar. A amônia, gás proveniente da decomposição microbiana dos dejetos dos animais é outra variável ambiental de grande relevância; se em grandes concentrações, também pode causar perdas significativas no desempenho das aves e dos trabalhadores (Miragliotta, 2000). Nas aves, entre outras coisas, é possível haver perda de apetite, com conseqüente perda de produtividade (Lott \& Donald, 2005)

Este trabalho identificou e quantificou diferenças no ambiente interno de dois galpões de poedeiras, por meio do monitoramento e posterior comparação estatística das variáveis ambientais: temperatura do ar, luminosidade, umidade relativa do ar, velocidade do ar, ruído, temperatura interna das telhas e concentração de amônia, com o objetivo de avaliar os efeitos da arquitetura de cada aviário no seu ambiente interno.

\section{MATERIAL E MÉTODOS}

Esta pesquisa foi realizada em uma granja de postura localizada no município de Bastos, SP. O clima da região é o Aw pela classificação de Köppen (Rolim et al., 2007), caracterizado por um clima tropical, com estação seca bem definida no período de inverno e temperaturas médias anuais maiores que $18^{\circ} \mathrm{C}$.

Foram registradas, em um ponto central no interior de dois aviários de postura, na altura das aves, as seguintes variáveis ambientais: temperatura do ar, umidade relativa do ar, ruído e luminosidade, utilizando-se um analisador de ambiente multi-funções modelo THDL-400 da fabricante Instrutherm ${ }^{\circledR}$; velocidade do vento, através de um anemômetro digital modelo AN-3010 da fabricante Icel $^{\circledR}$; temperatura interna da telha, com uso de um termômetro de infravermelho modelo Fluke 66 da fabricante Fluke ${ }^{\circledR}$; e concentração de amônia, utilizando-se um detector de gases modelo PAC7000 $\mathrm{NH}_{3}$ da fabricante Drager ${ }^{\circledR}$; posteriormente, esses dados foram analisados no programa computacional estatístico MINITAB ${ }^{\circledR}$.

O índice de temperatura e umidade (ITU), apesar de não considerar os efeitos da radiação, pode ser utilizado para resumir o conforto térmico em situações nas quais não se mediu a temperatura de globo negro. Brown-Brandl et al. (1997) 
apresentaram ITU adaptado para poedeiras, que é mostrado na equação (1) abaixo.

$$
\mathrm{ITU}=0,6 \times \mathrm{TBS}+0,4 \times \mathrm{TBU}
$$

onde: TBS é a temperatura de bulbo seco $\left({ }^{\circ} \mathrm{C}\right)$ e TBU é a temperatura de bulbo úmido $\left({ }^{\circ} \mathrm{C}\right)$.

Este índice foi calculado a partir dos dados registrados no ambiente e as condições de conforto verificadas em cada foram comparadas pelo teste não-paramétrico de KruskalWallis.

O estudo iniciou-se em março de 2007, nos dois galpões descritos a seguir, durante quatro semanas não consecutivas, totalizando 28 dias de monitoramento. As variáveis foram monitoradas nos seguintes horários: às 10, 11, 12, 14 e 15 h, tempo este considerado por Santos et al. (2005) como período crítico do dia. Esta metodologia de registros permitiu que os galpões fossem avaliados em semanas distintas nas quais os ambientes internos também foram distintos. A Tabela 1 aponta as características de cada um dos galpões estudados, enquanto a Figura 1 indica os cortes transversais dos dois galpões estudados.

Tabela 1. Caracterização dos galpões estudados

\begin{tabular}{lcc}
\hline Descrição & Galpão 1 & Galpão 2 \\
Latitude & $21^{\circ} 57^{\prime} 30^{\prime \prime}$ & $21^{\circ} 57^{\prime} 29^{\prime \prime}$ \\
Longitude & $50^{\circ} 42^{\prime} 05^{\prime \prime}$ & $50^{\circ} 42^{\prime} 03^{\prime \prime}$ \\
Altitude & $444 \mathrm{~m}$ & $456 \mathrm{~m}$ \\
Telha & Cimento amianto & Cerâmica \\
Lanternim & Sim & Não \\
Prolongamento do beiral (rabo de pato) & Sim & Não \\
Inclinação do telhado & $40 \%$ & $43 \%$ \\
Pé direito & $2,56 \mathrm{~m}$ & $2,32 \mathrm{~m}$ \\
Largura & $6,7 \mathrm{~m}$ & $7,0 \mathrm{~m}$ \\
Comprimento & $126,0 \mathrm{~m}$ & $140,0 \mathrm{~m}$ \\
Altura do pé & $2,0 \mathrm{~m}$ & $1,5 \mathrm{~m}$ \\
Gaiola (largura x profundidade x altura) & $50 \times 45 \times 45 \mathrm{~cm}^{-1}$ & $62 \times 63 \times 40 \mathrm{~cm}^{-1}$ \\
Densidade de aves & $\left(450 \mathrm{~cm}^{2} \mathrm{ave}^{-1}\right)$ & $\left(390 \mathrm{~cm}^{2} \mathrm{ave}^{-1}\right)$ \\
\hline
\end{tabular}

Ambos os galpões possuíam orientação leste-oeste, com as paredes leste e oeste fechadas com tábuas, e alojavam poedeiras da linhagem Hy-Line ${ }^{\circledR}$ w36, com 32 semanas de idade, no início do experimento.

Os dados obtidos de cada variável foram tabulados enquanto se realizou um teste de normalidade de AndersonDarling, no qual se constataram a não-normalidade e a nãosimetria na distribuição dos dados de todas as variáveis. Apesar de serem recomendados, nesses casos, testes nãoparamétricos de mediana ao invés de testes paramétricos de médias, neste trabalho se utilizaram gráficos de intervalo de confiança da média para uma análise visual dos resultados com base no Teorema do Limite Central, o qual diz que as médias tendem à normalidade quando calculadas a partir de uma amostra grande o suficiente (Costa Neto, 2002), Porém utilizou-se o teste de mediana não-paramétrico de KruskalWallis, que considera a não-simetria e a não-normalidade dos

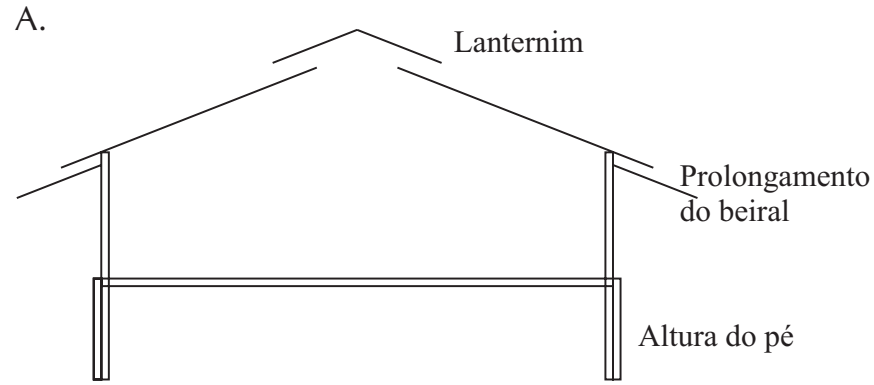

B.

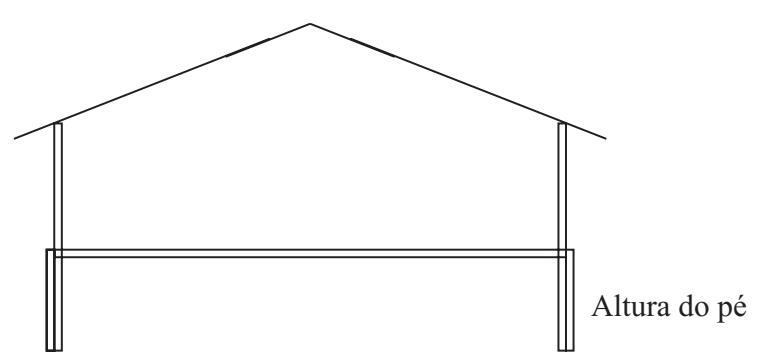

Figura 1. Esquema das seções transversais do A) galpão 1 e B) galpão 2

dados e dos resíduos, para confirmar os resultados pouco claros, observados nos gráficos.

Os dados de cada variável ambiental foram comparados entre os aviários com o intuito de se verificar as diferenças da tipologia e do material das coberturas nos ambientes térmicos internos; no entanto também se compararam as condições ambientais internas de cada aviário entre as semanas, com o intuito de se verificar a variação do ambiente térmico de cada galpão em diferentes condições de ambiente externo proporcionado pelas diferentes semanas de observação experimental.

\section{RESULTADOS E DISCUSSÃO}

Para a variável ambiental temperatura do ar (Figura 2A), na semana 1 os galpões apresentaram diferenças estatísticas significativas; o mesmo não se pôde afirmar para as segunda e quarta semanas; já na terceira semana e conforme o resultado do teste de Kruskal-Wallis evidenciou, os galpões foram considerados diferentes estatisticamente; curiosamente se observaram valores maiores de temperatura no galpão 2, recoberto com telha de cerâmica; tal medida pode ter ocorrido devido ao pé direito mais baixo deste galpão e à ausência de lanternim, o que dificulta a saída do ar quente do galpão pelo "efeito chaminé", conforme afirmam Mazon et al. (2006). Santos et al. (2005) também constataram os efeitos positivos do lanternim na saída do ar quente, em experimento com diferentes tipos de aviários. Tinôco (2001) afirma que o limite superior da temperatura do ar para conforto de poedeiras é de $28^{\circ} \mathrm{C}$. Observa-se na Figura 2A que apenas na semana 4 foram mensuradas temperaturas dentro da zona de conforto proposta pela autora.

A Figura 2B mostra o gráfico de intervalos de confiança da média para a variável luminosidade, no qual se pôde observar que na semana 1 os galpões apresentaram diferenças 
A.

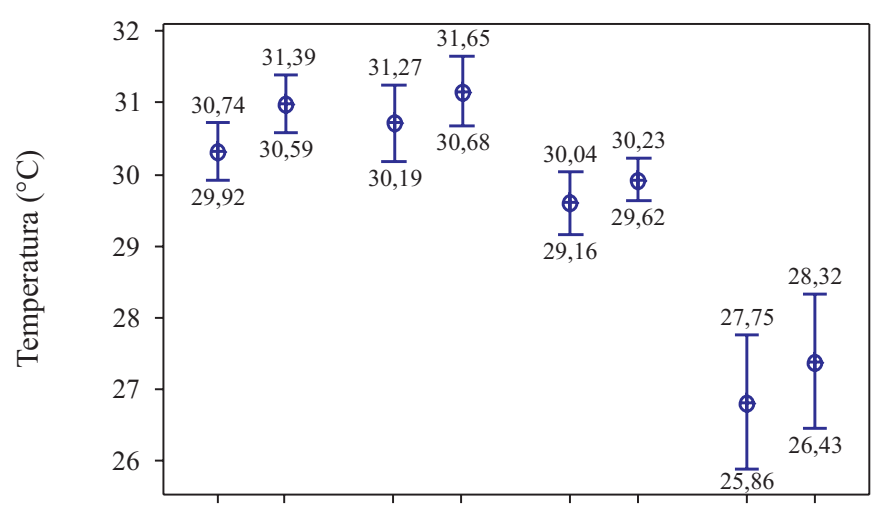

C.

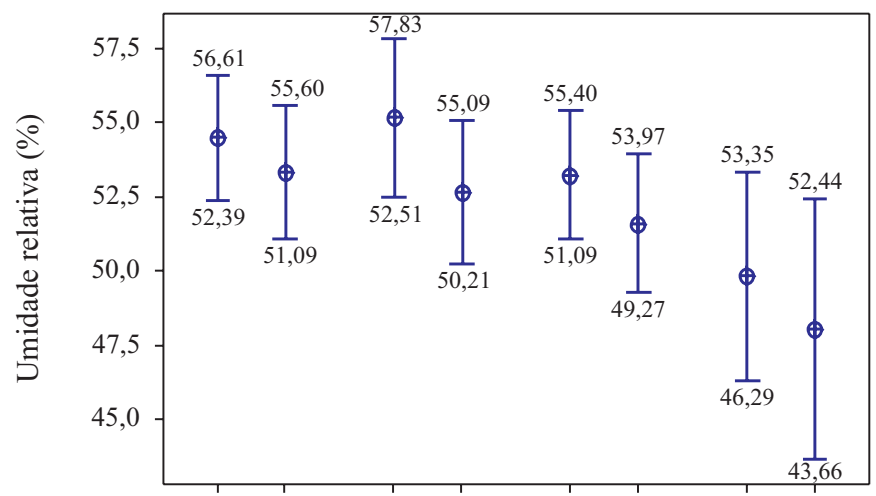

E.

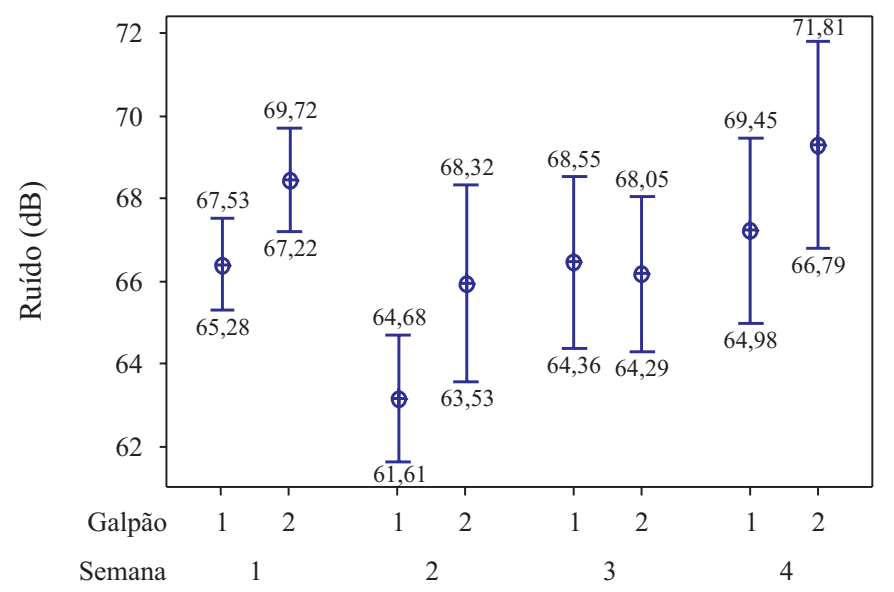

B.

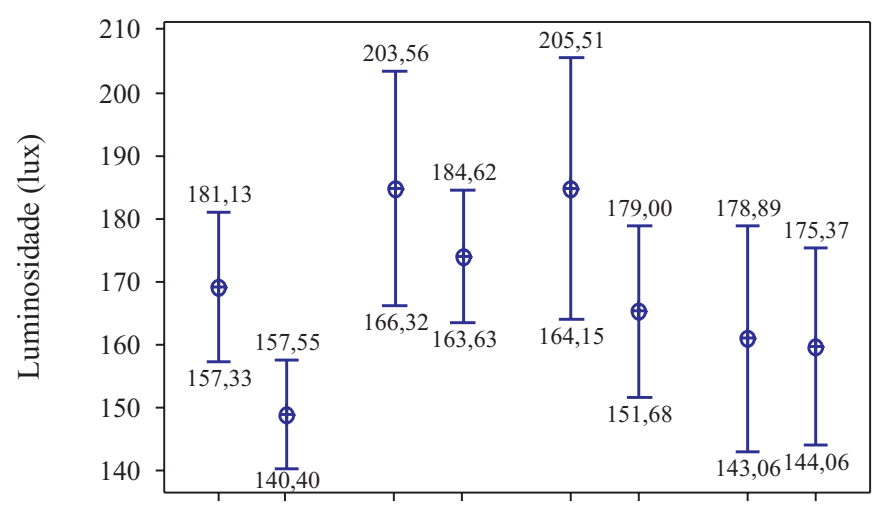

D.

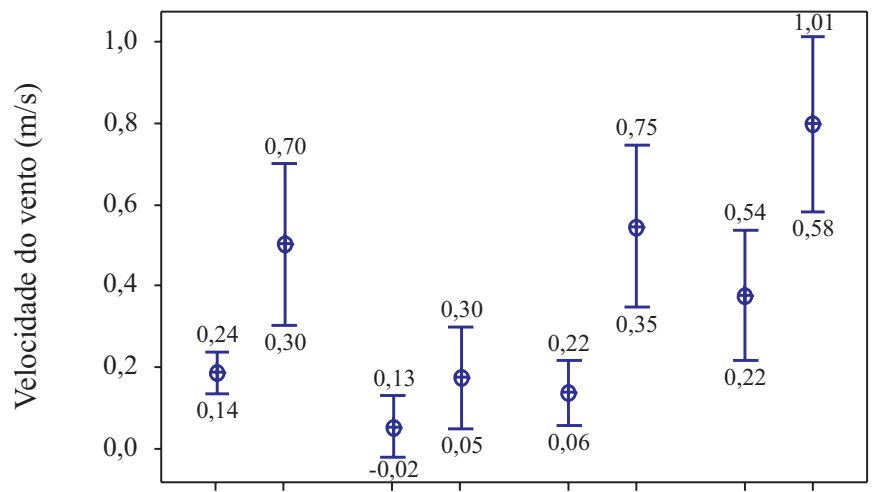

F.

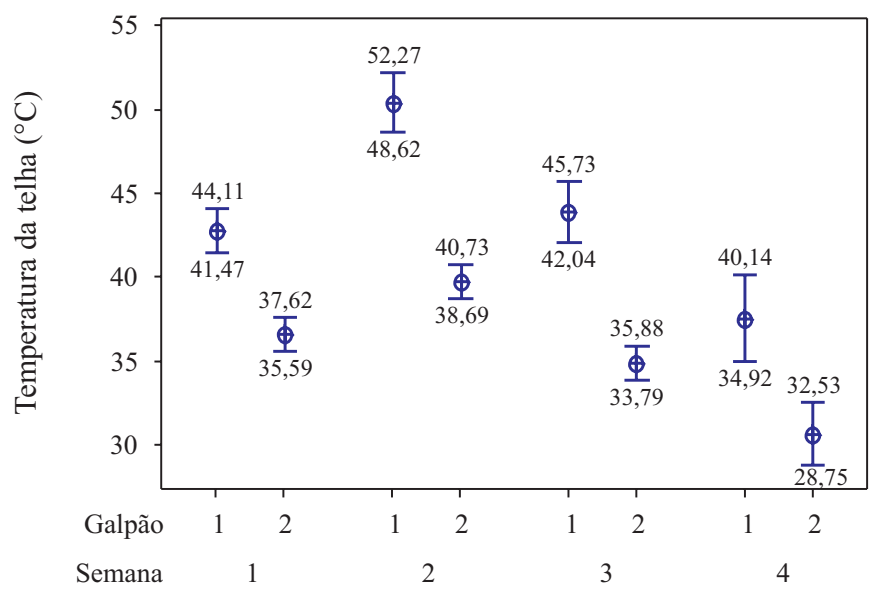

Figura 2. Intervalos de confiança da média da variável A) temperatura do ar, B) luminosidade, C) umidade relativa do ar, D) velocidade do vento, E) ruído e F) temperatura interna da telha, para todos os tratamentos combinados

significativas e, nas semanas 2 e 3, tem-se duas situações duvidosas em que se recorreu ao teste de Kruskal-Wallis, que indicou não haver evidências para afirmar que os conjuntos de dados são estatisticamente diferentes entre si ( $p>0,05)$. Na quarta semana, os galpões novamente não apresentaram evidências estatísticas para afirmar que são diferentes; no galpão 2 se observaram valores menores de luminosidade, quando comparado com o galpão 1; esta diferença de luminosidade ocorreu pelo fato do galpão 2 ter pé-direito menor que o galpão 1, dificultando a entrada de luz pelas laterais e também em virtude da cor interna da telha de cerâmica ser mais escura que a telha de cimento amianto, promovendo menor refletividade da luz dentro deste aviário; além disso, a presença de lanternim no galpão 1 proporcionou melhor iluminação natural no interior do galpão (Mazon et al., 2006).

O efeito da luminosidade no bem-estar de poedeiras é bastante complexo, haja vista que envolve a análise separada dos diferentes comprimentos de onda da luz na produção, na saúde e no comportamento das aves (Er et al., 2007). Renema et al. (2001), em experimento realizado com poedeiras, testaram os efeitos de diferentes intensidades de iluminação na produção de ovos, e observaram que em condições de iluminação acima de 500 lux a incidência de ovos menores foi significativamente maior ( $p>0,05)$ quando comparada com 
iluminações inferiores a 50 lux, sugerindo que intensidades luminosas muito altas promovem perdas na produção.

Na Figura 2C a umidade relativa do ar apresentou conjunto de dados estatisticamente iguais entre os galpões $1 \mathrm{e}$ 2 , nas quatro semanas, sendo que na segunda semana se fez conveniente consultar o teste não-paramétrico de Kruskal-Wallis. Não se pôde afirmar para cada galpão, na análise entre semanas, que houve diferenças entre os resultados das três primeiras semanas, sendo que estes resultados diferiram daqueles observados na quarta semana. Observa-se que os valores de umidade relativa do ar mensurados nas quatro semanas foram sempre inferiores a 70\%, valor este recomendado por Tinôco (2001) como limite da termoneutralidade.

Na Figura 2D, observa-se que a velocidade do vento do galpão 1 foi diferente daquela do galpão 2 nas quatro semanas observadas e a velocidade do vento no galpão 2 foi sempre maior. Para os resultados do galpão 1, na análise entre semanas, não se pôde afirmar que este foi diferente quando comparado entre as semanas 1 e 3 ; o mesmo foi observado com o galpão 2 e nos demais casos em que se observaram diferenças significativas; os valores absolutos de velocidade do vento do galpão 2 podem ser explicados pelo fato da renovação do ar só ter acontecido pelas aberturas laterais e, no galpão 1, a renovação do ar ter ocorrido principalmente pelo lanternim (Mazon et al., 2006), em razão do posicionamento do sensor no momento das medidas tomadas no local. Nääs (1989) afirma que ventos com velocidades inferiores a $0,2 \mathrm{~m} \mathrm{~s}^{-1}$ próximo aos animais, produzem efeito benéfico no seu bem-estar, porém, acima deste valor, os efeitos podem ser prejudiciais à saúde e provocar doenças pulmonares. Observa-se, na Figura 2D, que no galpão 10 vento sempre apresentou velocidades menores, estando mais próximo do limite estabelecido pela autora. Esta condição de ventilação favorável se deve à presença do prolongamento do beiral (chamado vulgarmente de "rabo de pato") deste galpão, que atua como barreira para a ventilação natural por "ação dos ventos".

No que se refere ao ruído nas primeira e segunda semanas, os resultados dos galpões 1 e 2 se comportaram de maneira diferente; já nas semanas 3 e 4 não foi possível afirmar que os galpões apresentaram diferenças significativas com relação a esta variável, conforme se pôde observar na Figura 2E. Comparando-se os mesmos galpões nas diferentes semanas observa-se que, no caso do galpão 1 , a terceira semana não difere da primeira e há evidências de que os tratamentos combinados da quarta e da segunda semana são diferentes; no galpão 2, comparando-se os resultados das semanas 2 e 3 e das semanas 1 e 4, não houve evidências para rejeitar a igualdade $(\mathrm{p}>0,05)$; pode-se, porém, afirmar que os resultados das semanas 1 e 4 diferem daqueles das semanas 2 e 3; para esta variável o galpão 2 apresentou valores absolutos maiores quando comparado com o galpão 1; ressalta-se que, nesta pesquisa, a principal componente do ruído medido foi a vocalização das aves e, conforme relatam Campo et al. (2005) este ruído pode refletir expressões de bem-estar. Considerando-se os limites para uma exposição diária de oito horas ao ruído, a que um trabalhador pode estar exposto, ambos os galpões mostraram níveis abaixo dos 85 dB recomendados pela norma NR-15 (MTE, 1978).

Os diferentes materiais de telha dos galpões 1 e 2 indicaram diferentes valores de temperatura interna de telha em todas as semanas, conforme se observa na Figura 2F; a telha de cimento amianto do galpão 1 sempre apresentou valores maiores de temperatura interna da telha, conforme também constatado por Santos et al. (2005) e Jácome et al. (2007); o galpão 1 mostrou-se diferente entre as duas primeiras semanas não se podendo, porém, afirmar esta diferença, comparando-se a primeira e a terceira semanas enquanto o galpão 2 se caracterizou como diferente nas quatro semanas; todavia, a menor temperatura da superfície interna da telha de cerâmica não propiciou temperaturas do ar menores no interior do galpão 2 (Figura 2A), conforme previsto (Tinôco, 2001); portanto, a presença do lanternim no galpão 1 foi fundamental para reduzir a temperatura interna deste aviário (Santos et al.,2005; Mazon et al., 2006); observa-se, nesta figura, que os valores de temperatura de telha são bastante elevados. De acordo com Savastano Jr. et al. (1997) e Sarmento et al. (2005), essas condições podem ser melhoradas com a pintura, em branco, da parte externa da telha.

Apresenta-se, na Tabela 2, o resumo dos resultados cujas combinações marcadas com um $\mathrm{X}$ representam as análises comparativas nas quais não se pôde afirmar diferença estatística para nível de significância de 5\%, conforme resultados do teste de Kruskal-Wallis.

Em ambos os galpões os valores de concentração de amônia medidos todos os dias, foram menores que 1 ppm e, portanto, não interferiram no bem-estar das aves pois, de acordo com Miragliotta (2000) e Lott \& Donald (2005), o limite para ao bem-estar de aves é de $20 \mathrm{ppm}$. Esses valores de concentração de amônia podem ser explicados pelo fato dos galpões escolhidos para as observações terem características construtivas que mantêm as fezes distantes das aves (piso elevado), aumentando a área de exposição das fezes com o ar (estrado de madeira entre o piso do galpão e o solo). Como as medidas de concentração de amônia foram tomadas na altura das aves, essas características dos aviários contribuíram significativamente para a dissipação do gás antes que este alcançasse as gaiolas.

Para melhor se comparar o conforto térmico entre os galpões, fez-se um teste não paramétrico de Kruskal-Wallis para verificar diferenças significativas $(p<0,05)$ das medianas do ITU calculado pela equação (1), proposta por Brown-Brandl (1997). Os resultados do teste são mostrados na Tabela 3.

O resultado do teste apresentado na Tabela 3 mostra que o ITU foi diferente entre os galpões durante todas as semanas de avaliação do ambiente. Este resultado evidencia as diferenças do ambiente térmico interno dos galpões estudados, conforme também constatado por Furtado et al. (2003), Jácome et al. (2007) e Santos et al. (2005). Em todas as semanas analisadas o ITU do galpão 2 foi superior aos observados no galpão 1. Considerando-se os limites de termoneutralidade relatados por Tinôco (2001) de $28^{\circ} \mathrm{C}$ para a temperatura do ar e $70 \%$ para a umidade relativa 
Tabela 2. Resumo dos resultados* obtidos pelo teste de Kruskal-Wallis

\begin{tabular}{|c|c|c|c|c|c|c|c|c|c|}
\hline & Variável & G1S1 & G1S2 & G1S3 & G1S4 & G2S1 & G2S2 & G2S3 & G2S 4 \\
\hline \multirow{6}{*}{ G1S1 } & Lux & $X$ & $X$ & & & & $X$ & $X$ & $x$ \\
\hline & $d B$ & $x$ & & $x$ & $x$ & & $x$ & $x$ & \\
\hline & $\mathrm{T}$ & $x$ & $x$ & & & & & & \\
\hline & Var & $x$ & & $x$ & & & $x$ & & \\
\hline & TT & $x$ & & $x$ & & & & & \\
\hline & UR & $x$ & $X$ & $x$ & & $x$ & $x$ & $x$ & \\
\hline \multirow{6}{*}{ G1S2 } & Lux & $X$ & $X$ & $X$ & & & & & \\
\hline & $d B$ & & $x$ & & & & & & \\
\hline & $\mathrm{T}$ & $x$ & $x$ & & & $x$ & $x$ & & \\
\hline & Var & & $X$ & $x$ & & & $x$ & & \\
\hline & $\mathrm{TT}$ & & $x$ & & & & & & \\
\hline & UR & $x$ & $x$ & $x$ & & $X$ & $x$ & & \\
\hline \multirow{6}{*}{ G1S3 } & Lux & & $X$ & $X$ & & & & & \\
\hline & $d B$ & $x$ & & $x$ & $x$ & $x$ & $x$ & $x$ & \\
\hline & $\mathrm{T}$ & & & $X$ & & & & & \\
\hline & Var & $x$ & $X$ & $x$ & & & $x$ & & \\
\hline & TT & $x$ & & $x$ & & & & & \\
\hline & UR & $x$ & $x$ & $x$ & & $X$ & $x$ & $x$ & \\
\hline \multirow{6}{*}{ G1S4 } & Lux & $X$ & & & $X$ & & & $X$ & $X$ \\
\hline & $d B$ & $X$ & & $X$ & $x$ & & $X$ & $X$ & $x$ \\
\hline & $\mathrm{T}$ & & & & $x$ & & & & $x$ \\
\hline & Var & & & & $x$ & $X$ & & $x$ & \\
\hline & TT & & & & $x$ & $X$ & & & \\
\hline & UR & & & & $x$ & & & $x$ & \\
\hline \multirow{6}{*}{ G2S1 } & Lux & & & & & $X$ & & & \\
\hline & $d B$ & & & & & $X$ & & & $x$ \\
\hline & $\mathrm{T}$ & & $x$ & & & $x$ & $x$ & & \\
\hline & Var & & & & $x$ & $X$ & & $X$ & \\
\hline & TT & & & & $x$ & $X$ & & & \\
\hline & UR & $x$ & $x$ & $x$ & & $x$ & $x$ & $x$ & \\
\hline \multirow{6}{*}{ G2S2 } & Lux & $X$ & & & & & $X$ & $X$ & \\
\hline & $d B$ & $X$ & & $x$ & $x$ & & $X$ & $x$ & \\
\hline & $\mathrm{T}$ & & $x$ & & & & $x$ & & \\
\hline & Var & $X$ & & $X$ & & & $X$ & & \\
\hline & $\mathrm{TT}$ & & & & & & $x$ & & \\
\hline & UR & $x$ & $x$ & $x$ & & $x$ & $x$ & $x$ & \\
\hline \multirow{6}{*}{ G2S3 } & Lux & $X$ & & & $X$ & & $X$ & $X$ & $X$ \\
\hline & $d B$ & $x$ & & $x$ & $x$ & & $x$ & $x$ & \\
\hline & $\mathrm{T}$ & & & $x$ & & & & $x$ & \\
\hline & Var & & & & $X$ & $X$ & & $X$ & \\
\hline & $\mathrm{TT}$ & & & & & & & $x$ & \\
\hline & UR & & & $X$ & $x$ & $X$ & $x$ & $X$ & \\
\hline \multirow{6}{*}{ G2S4 } & Lux & $x$ & & & $X$ & & & $X$ & $X$ \\
\hline & $d B$ & & & & $x$ & $x$ & & & $x$ \\
\hline & $\mathrm{T}$ & & & & $x$ & & & & $x$ \\
\hline & Var & & & & & & & & $X$ \\
\hline & TT & & & & & & & & $x$ \\
\hline & UR & & & & $x$ & & & & $x$ \\
\hline
\end{tabular}

* Combinações marcadas com um $X$ representam as análises comparativas nas quais o teste não permite afirmar diferença estatística para nível de significância de 5\%

Tabela 3. Teste de Kruskal-Wallis para as medianas* calculadas do ITU para as diferentes semanas e galpões analisados

\begin{tabular}{ccccc}
\hline \multirow{2}{*}{ Sistema } & \multicolumn{4}{c}{ Semanas } \\
\cline { 2 - 5 } & $\mathbf{1}$ & $\mathbf{2}$ & $\mathbf{3}$ & $\mathbf{4}$ \\
Galpão 1 & $27,8 \mathrm{Ab}$ & $27,7 \mathrm{Bb}$ & $26,3 \mathrm{Cb}$ & $24,3 \mathrm{Db}$ \\
Galpão 2 & $28,4 \mathrm{Aa}$ & $28,1 \mathrm{Ba}$ & $26,7 \mathrm{Ca}$ & $24,8 \mathrm{Da}$ \\
\hline
\end{tabular}

* As medianas seguidas das mesmas letras, maiúscula nas colunas e minúsculas nas linhas, não diferem entre si pelo teste para o nível de significância de 5\% do ar, tem-se que o limite de conforto térmico do ITU para poedeiras é de $26,2{ }^{\circ} \mathrm{C}$; constata-se, então, que os ambientes de ambos os galpões estiveram acima da zona de conforto térmico nas três primeiras semanas, enquanto na quarta semana se observou ITU dentro do limite calculado.

No que se refere ao resultado das variáveis ambientais de um mesmo galpão em função das variações do ambiente externo (semanas), não se pôde observar diferenças significativas devido à arquitetura e do material da telha.

\section{CONCLUSÕES}

1. Os gráficos de intervalo de confiança da média propiciaram resultados equivalentes ao teste não-paramétrico de Kruskal-Wallis em situações nas quais ambas as médias se encontravam fora ou dentro dos intervalos de confiança comparados, tendo sido importante para inferir as diferenças.

2. O estudo dos ambientes encontrados em cada galpão durante as quatro semanas de observação permitiu verificar diferenças significativas nas variáveis ambientais entre os galpões.

3. A análise dos dados não evidenciou melhores condições de conforto térmico no galpão recoberto com telhas de cerâmica, em virtude da tipologia do galpão, que não possuía lanternim e tinha o pé direito menor, dificultando a renovação do ar do aviário pela ventilação por "efeito chaminé”.

4. A concentração de amônia medida no interior das duas instalações ficou abaixo do limite de conforto estabelecido pela literatura.

5. O galpão recoberto com telhas de cerâmica apresentou valores maiores que do galpão recoberto com telha de cimento amianto, evidenciando os efeitos positivos do lanternim.

6. Recomenda-se para a região de Bastos, SP, que os aviários para galinhas de postura sejam construídos conforme a arquitetura do galpão 1 , porém com cobertura de telhas de cerâmica.

\section{AgRAdECIMENTOS}

Os autores agradecem a Sérgio Kenji Kakimoto e à granja Kakimoto, que cederam o espaço e propiciaram as condições necessárias para a execução desta pesquisa; à FAPESP, pela bolsa de Iniciação Científica, e ao CNPq, pelo auxílio financeiro (Processo n ${ }^{\circ}$ 476397/20).

\section{LITERATURA CITADA}

Brown-Brandl, T. M.; Beck, M. M.; Schulte, D. D.; Parkhurst, A. M.; DeShazer, J. A. Temperature humidity index for growing tom turkeys. Transactions of the ASAE, v.40, n.1, p.203-209, 1997.

Buffington, D. E.; Collasso-Arocho, A.; Canton, G. H.; Pit, D. Black globe-humidity index (BGHI) as comfort equation for dairy cows. Transactions of the ASAE, v.24, n.3, p.711-14, 1981. 
Campo, J. L.; Gil, M. G.; Dávila, S. G. Effects of specific noise and music stimuli on stress and fear levels of laying hens of several breeds. Applied Animal Behaviour Science, v.91, n.1, p.75-84, 2005.

Campos, E. J. Avicultura: Razões, fatos e divergências. Belo Horizonte: FEP-MVZ, 2000. 311p.

Costa Neto, P. L. O. Estatística, 2.ed., São Paulo: Edgard Blücher, 2002, 266p.

Esmay, M. L. Principles of animal environment. Co. Inc. $2^{\text {nd }}$. Westport: AVI Pub, 1982. 325p.

Er, D.; Wang, Z.; Cao, J.; Chen, Y. Effect of monochromatic light on the egg quality of laying hens. The Journal Applied Poultry Research, v.16, n.4, p.605-612, 2007.

Furtado, D. A.; Azevedo, P. V.; Tinôco, I. F. F. Análise do conforto térmico em galpões avícolas com diferentes sistemas de acondicionamento. Revista Brasileira de Engenharia Agrícola e Ambiental, v.7, n.3, p.59-564, 2003.

Jácome, I. M. T. D.; Furtado, D. A.; Leal, A. F.; Silva, J. H. V.; Moura, J. F. P. Avaliação de índices de conforto térmico de instalações para poedeiras no nordeste do Brasil. Revista Brasileira de Engenharia Agrícola e Ambiental, v.11, n.55, p.527-531, 2007.

Lott, B.; Donald, J. Amônia. Avicultura Industrial, n. 1111, 2003. Seção Ciência e Tecnologia: Manejo. http:// www.aviculturaindustrial.com.br>. 13 Out. 2005.

Mazon, A. A. O.; Silva, R. G. O.; Souza, H. A. Ventilação natural em galpões: o uso de lanternins nas coberturas. REM: Revista Escola de Minas, v.59, n.2, p.179-184, 2006.

Miragliotta, M. Y. Avaliação dos níveis de amônia em dois sistemas de produção de frangos de corte com ventilação e densidade diferenciadas. Campinas: FEAGRI/UNICAMP, 2000. 222p. Dissertação Mestrado
MTE - Ministério do Trabalho e Emprego. Norma regulamentar NR-15 atividades e operações insalubres, Anexo 1. Portaria n. 3.214. 1978.

Nääs, I. A. Princípios de conforto térmico. São Paulo: Ícone, 1989. 183p.

Nääs, I. A. Fatores não nutricionais que afetam o desempenho de frangos de corte. In: Conferência Apinco de Ciência e Tecnologia Avícola, 1992. Campinas. Anais... Campinas: FACTA, 1992. 12p.

Renema, R. A.; Robison, F. E.; Feddes, J. J. R.; Fasenko, G. M.; Zuidhoft, M. J. Effects of ligth from photostimulation in four strains of commercial egg layers: 2. Egg production parameters. Poultry Science, v.80, n.8, p.1121-1131, 2001.

Rolim, G. S.; Camargo, M. B. P.; Lania, D. G.; Moraes, J. F. L. Classificação climática de Köppen e de Thornthwaite e sua aplicabilidade na determinação de zonas agroclimáticas para o estado de São Paulo. Bragantia, v.6, n.4 p.711-720, 2007.

Santos, P. A.; Yanagi Júnior, T.; Teixeira, V. H.; Ferreira, L. Ambiente térmico no interior de modelos de galpões avícolas em escala reduzida com ventilação natural e artificial dos telhados. Engenharia Agrícola, v.25, n.3, p.575-584, 2005.

Sarmento, L. G. V.; Dantas, R. T.; Furtado, D. A.; Nascimento, J. W. B. do; Silva, J. H. V. Efeito da pintura externa do telhado sobre o ambiente climático e o desempenho de frangos de corte. Agropecuária Técnica, v.26, n.2, p.117-122, 2005.

Savastano Jr., H.; Silva, I. J. O.; Luz, P. H. C.; Faria, D. E. Desempenho de alguns sistemas de cobertura par aviários. Engenharia Rural, v.8, n.1, p.1-11, 1997.

Tinôco, I. F. F. Avicultura industrial: novos conceitos de materiais, concepções e técnicas construtivas disponíveis para galpões avícolas brasileiros. Revista Brasileira de Ciência Avícola, v.3, n.1, p.1-25, 2001. 